\title{
LA VENTA Y EL NOMBRAMIENTO DE OFICIOS EN EL CABILDO DE CORRIENTES DESDE FINES DEL SIGLO XVII Y PRIMERA MITAD DEL XVIII
}

\author{
The sale and designation of the cabildo of Corrientes offices since late seventeenth \\ century and first half of the eighteenth century
}

\section{Fernando Ariel Pozzaglio}

\begin{abstract}
Resumen
Hacia fines del siglo XVII, pese a la implementación del sistema de venta y renunciación de oficios, los regimientos del cabildo de Corrientes se hallaban indefectiblemente vacos dada la dificultad que se le presentaba a los vecinos para adquirir un oficio en propiedad. Ante el insistente pedido por parte del vecindario correntino, el gobernador de Buenos Aires accedió a nombrar a algunos vecinos locales para que se desempeñaran provisoriamente en algunos puestos de regidores y alguaciles mayores. Sin embargo, en la primera década del XVIII, y a lo largo de ese siglo, comenzaron a aparecer vecinos de Corrientes con títulos de propietarios de oficios del ayuntamiento. La permisión por parte de la Corona para adquirir un oficio mediante el pago de "frutos de la tierra" locales facilitó el acceso al cabildo a integrantes del grupo de estancieros y hacendados oriundos, dado el alza coyuntural de sus producciones agrícolas. No obstante, continuaron presentándose obstáculos para la continuación de los capitulares propietarios, dada la endeble comunicación de la Corona con una ciudad marginal como Corrientes, lo que ocasionó grandes dificultades y el cese en sus funciones de varios correntinos que se desempeñaban en algún oficio vendible del cabildo. Tras la enajenación de oficios, en el ayuntamiento de Corrientes no se produjo un cambio significativo de un grupo social por otro, sino una vinculación entre los antiguos vecinos, descendientes de los fundadores que tradicionalmente habían monopolizado el ingreso al cabildo, y los recién llegados, que fueron adquiriendo cargos capitulares, con el fin de hacer valer sus intereses personales y lograr beneficios recíprocos.
\end{abstract}

$$
<\text { Venta de oficios }><\text { Corrientes }><\text { Historia Colonial }><\text { cabildo }>
$$

\footnotetext{
Abstract

Until the end of the $17^{\text {th }}$ century, despite the establishment of a system to sell and renounce office jobs, the corps of the Corrientes cabildo was still unfailingly unable to fill their open positions. This situation was due to the difficulty presented by the heads of household, or vecinos, to buy such places. In response to persistent requests made by the local elite, the Buenos Aires governor decided to name officials to temporarily occupy the primary posts of regidor and alguacil. However, in the first decade of the $18^{\text {th }}$ century and throughout that century, vecinos proprietors of cabildo offices started to come into scene. The consent by the Crown of selling office posts in exchange for land products enabled
} 
Corrientes estancieros and landowners experiencing an economic boom to acquire such positions. Even so, the power and presence of these officials continued limited due to many obstacles still in place, more significantly the distance between Corrientes and the Crown, making communication scant. In the cabildo of Corrientes, differently from other cities, no significant change in the ruling social group took place following the expropriation of these posts, but in fact an association between the old vecinos, descendents of the founders, and the newly arrived officials; a linkage that was based on personal interests and having profit in mind.

$<$ Sale of office $><$ Colonial History $><$ Corrientes $><$ Cabildo $>$

\section{Introducción}

El presente trabajo de investigación tiene como objetivo abordar la temática de la designación y venta de oficios del cabildo de Corrientes durante los últimos años del siglo XVII y las primeras décadas del siglo XVIII. Esta investigación es la continuación de un estudio anterior que realizamos sobre esta temática en el periodo 1656-1679 (Pozzaglio, 2006). Si bien la cuestión de la enajenación de oficios capitulares ha sido estudiada en otras ciudades indianas no podemos afirmar lo mismo para el caso de Corrientes. Más allá de menciones de algunos datos referentes a la adquisición de oficios capitulares por algunos autores, (Mantilla, 1929; Gómez, 1928; Labougle, 1978) debemos aseverar que no se ha realizado hasta el momento un estudio que profundice sobre la cuestión en esta ciudad colonial. Por dicho motivo, constituye nuestro esencial objetivo cubrir este vacío en la historiografía de la región.

Previamente debemos establecer una diferenciación entre los oficios capitulares que fueron designados por el gobierno superior y aquellos que se desempeñaron tras su compra. Primeramente, abordaremos la cuestión de los nombramientos capitulares, para posteriormente adentrarnos en la temática de los oficios rematados.

De este modo, se intentó desentrañar cuáles fueron los oficios que se enajenaron durante este periodo y quiénes fueron los vecinos que los compraron. Asimismo, se logró conocer, en la medida en que las fuentes lo permitieron, cuál fue el medio de cambio utilizado y cuánto el monto que se pagó por cada uno de estos oficios del cabildo, como así también observar el tiempo en que se desempeñó cada capitular propietario en el puesto adquirido.

Esta investigación se realizó mediante un relevo y análisis de la información que nos brindan las actas capitulares y protocolos, documentaciones inéditas que se encuentran en el Archivo General de la Provincia de Corrientes.

\section{Contexto geográfico e histórico de Corrientes colonial}

Corrientes fue fundada el 3-IV-1588 por el adelantado Juan Torres de Vera y Aragón. La ciudad se emplazó en el margen izquierdo del río Paraná, en el lugar que antiguamente denominaban las Siete Corrientes, por las siete puntas que presenta su 
geografía en la orilla, formando remolinos o corrientes (Maeder, 1978).

La ubicación de la ciudad en tierras no inundables respondió a intenciones estratégicas debido a que, con esta fundación, no sólo se efectivizó la presencia española en la región mesopotámica, sino que además se constituyó como nexo necesario entre Asunción y Buenos Aires.

Su ubicación en una región marginal del virreinato peruano, denominado por los mismos correntinos como frontera de guerra, determinó que sus vecinos y moradores vivieran por un muy largo tiempo en constante peligro de ser atacado por distintas tribus indígenas aledañas no sometidas.

La ciudad correntina, siguiendoel modelocomúndelas urbes hispanoamericanas, se constituyó en forma de damero. Aquí, la plaza mayor tiene un carácter centralizador, lo cual no hace referencia exclusivamente a lo geográfico, dado que en el caso de Corrientes, ésta se halla cercana al margen del río, sino más bien se relaciona con la concentración de funciones políticas, religiosas, económicas, sociales y lúdicas, puesto que alrededor de la plaza se hallaban ubicados el cabildo, la iglesia matriz, y allí se realizan las distintas festividades religiosas y fiestas profanas.

Sin embargo, de acuerdo con las descripciones de los viajeros que visitaron la ciudad coinciden en señalar la precariedad de las viviendas construidas. Félix de Azara señaló que más que una urbe, Corrientes "era una confusa agregación de ranchos con claros puestos por casualidad" (Maeder, 1961).

La carencia de recursos y materiales de sus vecinos determinó un escaso desarrollo económico y poblacional. La moneda acuñada no circulaba en Corrientes, al igual que en otras ciudades del litoral, por lo que sus habitantes debieron utilizar el trueque o los productos de la tierra como medio de intercambio de sus limitados productos.

El cabildo, constituido al día siguiente de la fundación, organismo municipal indiano, estaba compuesto por dos alcaldes, un número variable de regidores que finalmente quedó determinado en seis, y ciertos oficios de preeminencia. Los primeros capitulares fueron nombrados por el adelantado. A partir de entonces, los miembros del cabildo salientes, que duraban un año en sus funciones, elegían a los nuevos integrantes lo que determinó, con el paso de los años y las alianzas entretejidas entre distintos vecinos, la conformación de una élite local, no homogénea, que fue modificándose con los años.

Tras la implementación y aplicación del sistema de venta y renunciación de oficios a mediados del siglo XVII en el Río de la Plata y, por ende, en Corrientes, los regimientos y los oficios de preeminencias del cabildo ya no serían electivos, sino que debían ser rematados al mejor postor. Esto trajo distintas consecuencias en la composición social de los ayuntamientos hispanoamericanos. Su incidencia en el de Corrientes es lo que se abordará en las siguientes líneas. 


\section{Nombramientos de los oficios del cabildo correntino}

Con el transcurrir de los últimos años del siglo XVII, continuó manifestándose entre los vecinos un desinterés o falta de recursos por adquirir un oficio en el cabildo correntino, por lo cual los regimientos y demás oficios continuaron vacos (Labougle, 1978). El desinterés por comprar, mediante remate público, un oficio capitular se relacionaba con las persistentes gestiones que se debía realizar para lograr finalmente su adquisición definitiva, lo que en muy raras ocasiones se lograba. Por otra parte, la falta de recursos estaba condicionada por la escasez y pobreza de la ciudad que se materializaba en una vida austera y sencilla en la mayor parte de los vecinos. A su vez, ambas causas podían estar vinculadas entre sí, dado que la limitación de recursos materiales de la región lograba que los correntinos se preocuparan más por la adquisición de bienes primarios, antes que arriesgarse a una empresa que parecía estar destinada al fracaso.

No obstante, no se debe limitar esta situación exclusivamente al ámbito local que estudiamos sino más bien hacerlo extensivo a otras localidades, según se desprende de una Real Cédula del 29.XI.1675, dictada a tal efecto ${ }^{1}$.

El gobernador de Buenos Aires, ante los constantes reclamos y solicitudes del cuerpo capitular correntino, intentó solucionar esta situación otorgando al cabildo correntino la facultad para elegir regidores, como en tiempos de la fundación, hasta que hicieran su aparición los propietarios. En 1679 el ayuntamiento, compuesto por los dos alcaldes ordinarios salientes, Juan Gómez de Meza y Francisco Sánchez Moreno, eligió seis regidores. Esta experiencia culminó abruptamente al no recibir estos nombramientos la aprobación de la Real Audiencia de Charcas, volviendo a quedar los regimientos correntino vacos por una década más.

La vacancia crónica trajo aparejado dos inconvenientes, uno local y otro general. El problema local estaba relacionado con la imposibilidad por parte de los alcaldes ordinarios para atender todas las cuestiones municipales, además de las exclusivas que se hallaban vinculadas con la justicia de primera instancia. La situación se agudizaba cuando uno de los alcaldes se ausentaba o fallecía, como sucedió en 1690, tras la muerte de Martín de Don Benito, alcalde de primer voto en función².

La otra problemática, de carácter general, estaba vinculada con el sistema financiero de la corona hispánica. La inexistencia de regidores en los últimos años provocaba consecuentemente la ausencia del pago de la media anata, impuesto real que otorgaba ingresos, aunque escasos, a la Caja Real de la hacienda local, perjudicando de este modo los intereses del monarca español.

Para evitar estos perjuicios y dadas las facultades que otorgaban las reales provisiones a los gobernadores, José de Herrera de Sotomayor, quien ocupó este cargo en la provincia del Río de la Plata entre 1682 y 1691, nombró a Ambrosio de Acosta

\footnotetext{
${ }^{1}$ La Real Cedula se halla transcripta en el Archivo General de la Provincia de Corrientes, Actas Capitulares 12, fs.1-4. (en adelante AGPC, AC)

${ }^{2}$ AGPC, AC 10, f. 144v.
} 
y Víctor de Figueroa, vecinos feudatarios, regidores del cabildo correntino, en 1690 y 1703, respectivamente.

Dado que el principal motivo por el cual se designaban capitulares había sido el perjuicio ocasionado a la Real Hacienda, los regidores nombrados por el gobierno superior debían ingresar en la Caja Real dies pesos de a ocho reales de plata por cada un año de lo que sirvieren en el dicho oficio ${ }^{3}$. Este pago fue fijado teniendo presente los escasos recursos que podían otorgar los vecinos que se desempeñaban en un oficio del cabildo correntino.

Por tanto, el gobierno superior de Buenos Aires continuó nombrando capitulares, esta vez ya no sólo regidores sino también alguaciles mayores. Ocuparon este puesto, consecutivamente, en distintos periodos, los vecinos Luis de Almada (1690), Félix Sánchez Moreno (1690-1697), Jácome Pérez Lindo (1697-1701) y Adrián de Esquivel (1703-1704). Por otra parte, también se continuó expidiendo títulos a vecinos para que ejercieran el cargo de regidores del cabildo, como a Diego Fernández (1703-1709) y a Pascual Ramírez (1697-1703). Mientras que estos últimos se vieron obligados a pagar 10 pesos anuales, los vecinos que ocuparon el puesto de alguacil mayor, dado que este era un cargo de mayor preeminencia, se les solicitó enterasen a la Caja de la Real Hacienda 12 pesos. La excepción en este caso fue Sánchez Moreno, quien desembolsó 25 pesos, sin que podamos saber el motivo puntual de este aumento del pago 4 .

La elección de estos vecinos por parte del gobernador recayó, como mencionan sus títulos expedidos, por ser persona benemerita y concurrir todas las calidades en su persona, tal como lo estipulaban las reales leyes (Bayle, 1952). Esta generalidad manifestada en los títulos, a nuestro entender, no sólo por su oriundez, sino que además se relacionaba con la experiencia que estos vecinos poseían en la administración local, ya que la mayoría de los nombrados ocuparon alguna vez un cargo en el ayuntamiento local.

Así también, dado que los vecinos que ocuparon un puesto en el cabildo de Corrientes, ya sea un regimiento o alguacilazgo, lo fueron por nombramiento del gobernador del Río de la Plata, su duración en el cargo estuvo supeditada, de acuerdo con el título expedido, a la aparición de un rematador del oficio o, en su defecto, hasta que el gobierno superior dispusiese lo contrario ${ }^{5}$. Sin embargo, las causas por las cuales estos vecinos cesaron en el desempeño de sus oficios no siempre fueron las indicadas. Víctor de Figueroa, Pascual Ramírez y Félix Sánchez Moreno hicieron dejación de sus oficios, por su propia voluntad, luego de varios años de ejercicio en los mismos (seis años los primeros y siete el tercero). Sánchez Moreno fundamentó la decisión de renunciar al cargo dado en la necesidad de tener mayor tiempo disponible para atender a actividades personales, las cuales estaban relacionadas con sus actividades agrícolas ${ }^{6}$.

\footnotetext{
${ }^{3}$ AGPC, AC 11, f. 218v.

${ }^{4}$ AGPC, AC 12, f. 13.

${ }^{5}$ AGPC, AC 11, f. 220v.

${ }^{6}$ AGPC, AC 13, f. 102.
} 
Por otra parte, tanto Ambrosio de Acosta como Diego Fernández fallecieron en el ejercicio de los oficios, mientras que Adrián de Esquivel, fue separado del cargo por haber sido condenado y desterrado de la ciudad correntina por la implicancia en un delito cometido contra el convento de Nuestra Señora de la Merced7.

\section{Cuadro 1}

Nombramiento de capitulares

\begin{tabular}{|c|c|c|c|c|c|}
\hline Vecino & Nombramiento & Monto del pago & \multicolumn{2}{|c|}{$\begin{array}{c}\text { Año } \\
\text { inicio }\end{array}$} & \multicolumn{1}{c|}{$\begin{array}{c}\text { Motivo } \\
\text { del cese }\end{array}$} \\
\hline $\begin{array}{c}\text { Ambrosio de } \\
\text { Acosta }\end{array}$ & Regidor decano & $\begin{array}{c}10 \$ \text { de a } 8 \text { reales } \\
\text { anuales }\end{array}$ & 1690 & 1696 & Fallecimiento \\
\hline Luis de Almada & Alguacil mayor & $\begin{array}{c}12 \$ \text { de a } 8 \text { reales } \\
\text { anuales }\end{array}$ & 1690 & 1690 & Reemplazo \\
\hline $\begin{array}{c}\text { Adrián de } \\
\text { Esquivel }\end{array}$ & Alguacil mayor & $12 \$$ & 1703 & 1704 & Suspensión \\
\hline $\begin{array}{c}\text { Diego Fernánde } \\
\text { Fíctor de } \\
\text { Figueroa }\end{array}$ & Regidor decano & $\begin{array}{c}10 \$ \text { de a } 8 \text { reales } \\
\text { anuales }\end{array}$ & 1713 & 1719 & Fallecimiento \\
\hline $\begin{array}{c}\text { Jácome Pérez } \\
\text { Lindo }\end{array}$ & Alguacil mayor & $\begin{array}{c}12 \$ \text { de a } 8 \text { reales } \\
\text { anuales }\end{array}$ & 1697 & 1701 & $\begin{array}{c}\text { Dejación de } \\
\text { oficio }\end{array}$ \\
\hline $\begin{array}{c}\text { Pascual Ramírez } \\
\text { oficio }\end{array}$ \\
\hline $\begin{array}{c}\text { Félix Sánchez } \\
\text { Moreno }\end{array}$ & Regidor decano & $\begin{array}{c}10 \$ \text { de a } 8 \text { reales } \\
\text { anuales }\end{array}$ & 1697 & 1703 & $\begin{array}{c}\text { Dejación de } \\
\text { oficio }\end{array}$ \\
\hline
\end{tabular}

Fuente: elaboración propia basada en Actas Ctes.

\section{El sistema de venta y renunciación de oficios capitulares}

La venta de los oficios capitulares en tierras hispanoamericanas se efectuó realizando un mecanismo preciso, estipulado por las leyes reales que configuraron el sistema (Tomás y Valiente, 1982). Ante la vacancia de un cargo en el ayuntamiento, el gobierno superior autorizaba al tesorero juez oficial a que sacara a remate determinado oficio con el fin de conseguir un comprador.

El lugar determinado para la ejecución de la almoneda era el sector de la plaza mayor que daba justo frente a los portales de las casas del cavildo ${ }^{8}$. Allí se tocaba la

\footnotetext{
${ }^{7}$ El gobernador Alonso Valdés de Inclán realiza las averiguaciones pertinentes sobre los excesos que constan por querellas dada en este gobierno cometio el capitan Joseph Fernandez Montiel en el despojo violento que hizo de una esclaba nombrada Agustina del convento de Nuestra Señora de la Merced de la ciudad de San Juan de Vera de las Siete Corrientes. AGPC, AC 14, f.50.

${ }^{8}$ En la gran mayoría de todos los autos y disposiciones de venta de oficios figura que los pregones se realizaban en la plaza mayor, frente al cabildo. Véase, por ejemplo, Archivo General de la Provincia de Corrientes, Actas Capitulares 19, f. 55v (en adelante AGPC, AC).
} 
caja de guerra, a efecto de reunir algunos vecinos y moradores de la ciudad, y por voz de pregonero, ejercido por algún esclavo, se anunciaba el oficio que se ponían a la venta ${ }^{9}$. Generalmente, las subastas se efectuaban en los horarios de la tarde ${ }^{10}$. De acuerdo con leyes reales, estaba estipulado que primeramente se realizasen treinta remates consecutivos, los cuales debían ejecutarse en la ciudad donde se ejercería el cargo a comprar. Por lo común, sobre todo en casos de falta de postores, se ordenaba realizar otros tantos pregones más ${ }^{11}$.

Posteriormente, nueve remates debían realizarse en la ciudad de Buenos Aires con el fin de conseguir nuevas pujas y el consecuente aumento del precio ofrecido por el oficio vendible. Quien estipulase mejor forma de pago y mayor cuantía era en quien se subastaba finalmente el cargo (Bayle, 1952).

Una vez vendido el oficio en el mejor postor, el adquiriente o, en la mayoría de los casos su apoderado, solicitaba al gobernador el otorgamiento del título de capitular propietario. Antes de tomar posesión del mismo, el comprador, previo ingreso en la Caja de la Real Hacienda local del monto convenido en el remate, se hallaba obligado a efectuar el pago de la media anata y el de la conducción.

El primer impuesto, es decir la media anata, era un derecho que se imponía a los oficios vendibles o renunciables, cuyo porcentaje fue variando de acuerdo con la época. En este periodo, el cobro del derecho de media anata en Corrientes estuvo situado en $5 \%$ del valor en que era enajenado el mismo. Por otra parte, la conducción del derecho de media anata, asimismo, era un impuesto equivalente a 1,2\% del monto total vendido ${ }^{12}$.

Una vez presentadas las certificaciones otorgadas por parte del tesorero juez oficial de la ciudad de Corrientes de haber cumplido con estas obligaciones financieras, el adquiriente se encontraba en condiciones de exhibir ante el cabildo el título de capitular propietario para tomar posesión del mismo, previa realización del juramento de fidelidad acostumbrado.

En ciertos casos, sobre todo cuando el cargo capitular adquirido se pagaba en cuotas, se obligaba a los adquirientes del oficio a presentar fiadores, aceptados previamente por el oficial real, los cuales garantizaban con sus bienes el buen desempeño del vecino en sus funciones capitulares ${ }^{13}$.

No obstante, aún después de cumplimentados estos pagos y estipulaciones, el comprador del oficio no podía sentirse definitivamente dueño del mismo, dado que en el título correspondiente, otorgado por el gobernador de la provincia, existía una cláusula por la cual se establecía la obligación ineludible de presentar confirmación de Su Magestad y señores de su Real y Supremo Consejo de las Indias dentro de seis años

\footnotetext{
${ }^{9}$ Véase AGPC, AC 19, f.34v.

${ }^{10}$ Véanse por ejemplo AGPC, AC 18, fs. 142, 167-168 y AC 19, fs. 55, 58, 140.

${ }^{11}$ Véanse AGPC, AC 18, fs. 134 y 138.

${ }^{12}$ Véase AGPC, AC 18, f. 186 en donde se encuentran bien detallado el cobro de estos impuestos que se realiza a Jorge Martínez de Ibarra por su remate del oficio de alcalde provincial de la santa hermandad.

${ }^{13}$ Véase AGPC, AC 15, fs. 46v y 60; AC 16, fs.59 y 63v.
} 
que an de correr y contarse desde el día del remate que de el se hizo y no lo haziendo a de quedar vaco... ${ }^{14}$.

Asimismo, en el título que se le entregaba se hacía extensivo al comprador del oficio la prohibición inmanente que tenían los miembros del cabildo de ausentarse de la ciudad por tiempo superior a ocho meses sin licencia deste gobierno no iendo a cosas del real servicio o utilidad de ella. ${ }^{15}$

Como veremos más adelante, muchos fueron los vecinos que perdieron sus puestos por incumplimiento de esta cláusula.

\section{Formas de pago de los oficios}

Debemos preguntarnos en estos momentos de qué modo se efectuaba el pago por los oficios del cabildo, y si es posible observar cuáles eran los distintos gastos que comúnmente debieron llevar a cabo los vecinos que quisieran poseer en propiedad un cargo capitular. Para adentrarnos a este punto, debemos previamente puntualizar qué características poseyó el sistema monetario rioplatense durante este periodo.

Distintos estudios económicos, nos permiten aseverar que en la ciudad de Corrientes, al igual que en la mayoría de las ciudades marginales del virreinato peruano, no circularon monedas metálicas a los largo de toda la época colonial (Maeder, 1977).

Un acta capitular, fechada en 18.IX.1738, es bien explícita al mencionar que en esta ciudad no ay moneda sellada y que las monedas son frutos que se reducen a cambios uno por otro ${ }^{16}$. Estos "frutos" que se mencionan en el documento son las denominadas "moneda de la tierra" que en Corrientes, a falta del metálico, se utilizó como medio de cambio en el mercado local. En este sentido, para poder ser utilizado como "moneda de la tierra", un producto debía reunir algunas condiciones como estar disponible, pero a la vez ser limitado en el ámbito local; ser requerido por el grupo de personas de la ciudad y sobre todo ser un producto durable y potencialmente divisible y reagrupable, sin la consecuente pérdida del valor (Gelman, 2003).

Generalmente en Corrientes, se utilizaba la vara de lienzo de algodón como moneda, si bien, cuando se produjo la escasez de este producto, se utilizaron otros como yerba, tabaco, azúcar y cuero. Asimismo, se señalaron como monedas "mas nobles" el hilo común, la quínoa de algodón, el algodón mismo y el cuero blanco, solo por nombrar los más destacados. La regulación de estos productos era fijada comúnmente por el cabildo que establecía el precio nominal de cada uno de estos, publicando inmediatamente su resolución por auto, para su conocimiento general. Con estas "monedas de la tierra" señaladas se efectuaba el pago tanto de los impuestos reales, como el de la media anata, la sisa, como así también de las limosnas de la santa cruzada o derechos eclesiásticos, como el diezmo.

\footnotetext{
${ }^{14}$ AGPC, AC 18, f. 169v.

${ }^{15}$ AGPC, AC 19, f. 144v.

${ }^{16}$ AGPC, AC 23, f. 58.
} 
La corona, ante el conocimiento de la realidad material de las ciudades periféricas como Corrientes, consintió el pago de estas contribuciones en estas "monedas de la tierra". Del mismo modo, permitió que los oficios vendibles se solventaran con el pago en estas especies. En la documentación que transcriben los remates figura de forma general que el postor habría de realizar el pago en las monedas en que se hazen los enteros en esta Real Caja, a los cuales también se los denominó frutos y jeneros de aquel país sin especificar la especie ${ }^{17}$.

Esta generalización que muchas veces aparecen en las fuentes, se torna comprensible si se tiene en cuenta que, por provisión del gobernador del Río de la Plata y los oficiales reales, se estipuló que como afirma uno de los autos proveídos, se equipare cada peso de las corrientes en quatro rreales puestos en esta ciudad (de Buenos Aires) y que no se admita otra postura en otra especie mas que en la dicha y costo a baras de lienzo de algodón en aquella real caja... ${ }^{18}$

Por dicho motivo, los pagos que realizaron los vecinos en las Cajas Reales por los oficios fueron en varas de lienzo de algodón, aunque también se permitió en otros géneros. Fue común además el pago con yerba de la que se comercia en el Paraguay, tal como lo hicieron en las posturas de Adrián Cabrera Cañete y Fernando Esquivel y Cabrera. Esto nos daría una pauta para comprender a qué grupo social pertenecerían los capitulares propietarios de Corrientes, tema que abordaremos más adelante.

Fue usual, y aceptado por el gobierno superior, que en las pujas, los interesados expusieran de qué modo habría de efectuarse el pago del oficio. Generalmente se efectuaba sólo una parte del monto total en contado antes de entrar a ejercer el oficio, el resto podría financiarse, según la postura hecha, en varios plazos anuales, que de forma habitual iban de dos a cuatro cuotas, llegando incluso a aceptarse un total de cinco términos. En estas situaciones es cuando aparecía la necesidad de presentar por parte del rematador del oficio uno o varios fiadores a satisfacción de dichos juezes oficiales reales, que garantizarían con su solvencia, en caso de incapacidad económica del comprador, la liquidación del monto estipulado.

\section{La venta de regimientos del cabildo}

Posteriormente al fallecimiento del regidor Diego Fernández, capitular nombrado por el gobernador rioplatense, los regimientos del cabildo correntino volvieron a quedar vacos por espacio de cuatro años, hasta que en 1713 comenzaron a aparecer vecinos que presentaron títulos de regidores que lo adquirieron en remate público.

Previamente, debemos preguntarnos por las causas que permitieron la aparición de un gran número de vecinos interesados, con recursos disponibles para comprar un oficio del organismo municipal.

\footnotetext{
${ }^{17}$ Véanse AGPC, AC 17, f. 155; AC 18, fs. 141, 167; AC 19, f. 58; AC 21, f. 51.

${ }^{18}$ AGPC, AC 16, f. 57.
} 
Para comprender esta situación debemos considerar los cambios económicos que comenzaron a producirse en Corrientes por causa de la expansión de su frontera y la conformación y lento desarrollo de las estancias y chacras en su jurisdicción. La ganancia que aportó la producción agrícola en mayor medida permitió a un grupo de vecinos, generalmente estancieros y hacendados, obtener recursos con los cuales solventar el pago del remate. Sobre todo si se tiene en cuenta que, en virtud a la Reales Cédulas, como hemos visto anteriormente, se permitió a las ciudades pequeñas en donde no circulaba metálicos, como moneda de intercambios, efectuar el pago de los impuestos reales, como así también el de los oficios, con especies y productos de la tierra $^{19}$.

Si bien los alcaldes ordinarios constituyeron el primer brazo del cabildo, los regidores constituyeron el segundo, siendo sus funciones básicas el administrar los núcleos urbanos. Es de destacar que, desde la segunda década del siglo XVIII, se comenzó a denominar "veinticuatro" a los regidores correntinos, que si bien, en la península hispánica, este título estuvo reservado para los regidores que poseían rango nobiliario y ostentaban una posición social acomodada, en Corrientes, en esta época, comenzó a nombrarse con este apelativo indistintamente a la totalidad de regidores, llegando a constituirse en un equivalente (Piñal, 1989) ${ }^{20}$.

Durante el periodo 1713 a 1728, catorce vecinos presentaron ante el cabildo correntino sus títulos de regidores, de los cuales uno, Pedro Ruiz de Bolaños, lo hizo llamativamente en dos oportunidades.

Como podemos observar en el cuadro, pese a ser en propiedad los oficios rematados en la mayoría de los casos, no fue muy prolongado el tiempo en que los vecinos correntinos se desempeñaron en los regimientos.

Algunos de los propietarios (como Fernando Gómez Durán, Juan Eusebio de Chávez, Pedro Ruiz de Bolaños, Ignacio de Villanueva, Domingo de Galarza e Ignacio Soto) lo hicieron por el lapso de seis años. La mayoría de estos vecinos cesaron en su puesto por falta de confirmación real, como veremos, a excepción de Soto que, por cuenta propia, hizo renunciación del oficio en cabeza de Su Majestad.

Isidro Enríquez de Lara y Gerónimo Martínez de Ibarra se desempeñaron, hasta su fallecimiento, como regidores propietarios alrededor de tres años, mientras que otros tres vecinos (Pedro Ruiz de Bolaños, Juan Vargas Machuca, Bartolomé Rodríguez) ocuparon el puesto sólo por un año

\footnotetext{
${ }^{19}$ Estos datos nos aportan, aunque de forma parcial, las actas del cabildo, las cuales, en algunas sesiones capitulares es común informar que no asistieron determinados capitulares por estar ausentes en sus estancias y hasiendas.... Véase AGPC, AC 16, f. 16 (13.IX.1728).

${ }^{20}$ En la península ibérica, los cabildos inicialmente estuvieron compuesto por veinticuatro regidores, de ahí el título "caballero veinticuatro" con el que se lo designaba. En Sevilla, por ejemplo, la "veinticuatría", como se la denominó, constituyó en una de las más rancias instituciones de la ciudad. Hacia fines del siglo XVIII, estos estuvieron representados por a 60 individuos provenientes de las más distinguidas familias sevillanas. La veinticuatría, poseyó un origen militar y se caracterizó por ser de nombramiento real designados entre la selecta nobleza de la ciudad andaluza.
} 


\section{Cuadro 2}

Regidores propietarios del cabildo correntino

\begin{tabular}{|lccc|}
\hline \multirow{2}{*}{\multicolumn{1}{|c}{ Regidor propietario }} & \multicolumn{2}{c}{ Año } & \multirow{2}{*}{ Precio } \\
\cline { 2 - 3 } Sebastián de Villanueva & Ingreso & Cese & - \\
\hline Fernando Gómez Durán & 1713 & 1732 & $320 \$$ \\
\hline Joseph Antonio Miérez & 1713 & 1719 & \\
\hline Martín Cordero & $1715-$ & 1729 & $304 \$$ \\
\hline Juan Eusebio Chávez & 1715 & 1720 & $300 \$$ \\
\hline Gerónimo Martínez de Ibarra & 1720 & 1726 & - \\
\hline Isidro de Enríquez de Lara & 1720 & 1722 & $300 \$$ \\
\hline Francisco Molina Salazar & 1721 & 1724 & - \\
\hline Pedro Ruiz de Bolaños & 1722 & 1736 & $455 \$$ \\
\hline Juan de Vargas Machuca & 1722 & - & $400 \$$ \\
\hline Ignacio de Villanueva & 1732 & 1737 & $400 \$$ \\
\hline Domingo de Galarza & 1725 & & $500 \$$ \\
\hline Ignacio de Soto & 1725 & 1731 & $310 \$$ \\
\hline Bartolomé Rodríguez & 1725 & 1731 & - \\
\hline
\end{tabular}

Fuente: elaboración propia en base a Actas Ctes.

No obstante, pese a las limitaciones anteriormente señaladas, debemos mencionar que tres vecinos se desempeñaron como regidores propietarios por un tiempo prolongado. Mientras que Joseph Antonio Miérez y Francisco Molina Salazar estuvieron en sus cargos por espacio de catorce años, Sebastián de Villanueva permaneció en el suyo diecinueve. Estos vecinos pudieron ejercer su oficio de regidor por mayor tiempo debido a que pudieron conseguir la confirmación del rey.

Ahora bien, debemos preguntarnos cuál fue el precio por el que se remataron los regimientos en el cabildo correntino durante este periodo. El cuadro 2 nos detalla particularmente cuánto se pagó por cada uno de ellos, si bien debemos reconocer que los datos que se presentan se hallan incompletos, dado que en algunos casos no hemos podido hallarlos en las documentaciones con la que trabajamos.

No obstante, las informaciones expuestas nos permiten tener una idea más precisa de la situación. Nos encontramos que el precio más elevado por el cual se compró un regimiento fue pagado por Domingo de Galarza, ascendiendo éste a 500 
pesos el remate final. Luego, nos encontramos con que el monto más frecuentemente abonado por el oficio de regidor fue de 400 pesos, como los hicieron Juan Vargas Machuca e Ignacio de Villanueva, o 455 como Pedro Ruiz de Bolaños.

Sin embargo, creemos que el precio base por el cual se iniciaba el remate de un regimiento fue de 300 pesos. A este precio lo remataron Juan Eusebio de Chávez e Isidro de Enríquez de Lara. Esto se debió a que, probablemente, no se presentó ningún opositor en las almonedas, manteniéndose de este modo invariable el importe del mismo.

Probablemente el aumento de los precios desembolsados de los oficios estuvo relacionado exclusivamente con el número de rematadores y la disponibilidad de recursos materiales para solventar el costo de la puja por parte de los interesados por adquirir el oficio.

\section{La enajenación de la escribanía}

Uno de los oficios de mayor importancia fue sin duda alguna el de escribano del cabildo. La sobreestimación de este "oficio de pluma", fue producto de la mentalidad legalista española, según la cual todas las acciones públicas debían ir asentadas por escrito y legalizada con la fe del escribano. Por este motivo, el oficio de notario otorgó un prestigio social y un estatus considerable a quien lo desempeñó (Álvarez, 1987).

El escribano no fue en esencia un oficio capitular, ya que sus labores no sólo se relacionaban con las acciones de aquella institución municipal, sino que además debía redactar los documentos judiciales, protocolos, tasaciones, testamentos, los cuales debía rubricarlos.

Por dicho motivo, para poder adquirir el oficio de escribano, ya sea por arrendamientos o compra, debía el aspirante ser previamente examinado en Buenos Aires por el asesor general de gobierno y abogado del reino (Guajardo Fajardo, 1995). Dice una provisión:

quien para efecto de exsaminarle le hiso varias preguntas y repreguntas tocantes a la obligación del oficio del escrivano y forma de actuar las causas y negocíos sívíles o criminales y executívos; y asimismo le hiso diferentes preguntas tocantes a varios instrumentos y contratos publicos y a todas ellas respondio con prontitud por cuía raçon le hallo apto para execra el oficio de escrivano que ha rematado con lo qual se concluío esta diligencia... ${ }^{21}$

En la venta o arrendamiento del oficio de escribanos en Corrientes, en sus respectivos títulos se mencionan dos tipos de escribanías, las públicas y las públicas de

\footnotetext{
21 AGPC, AC 20, f. 83.
} 
número ${ }^{22}$, ambas con actuación en el cabildo. Las escribanías de número eran aquellas que correspondían a las que estaban aprobadas y asignadas a una determinada ciudad. Estos escribanos podían tener a su cargo exclusivo la redacción de ciertos documentos relacionados con la justicia, actas del cabildo, de la cárcel, etc.

Por otra parte, las escribanías que no eran de número, pese a no corresponder exclusivamente a la jurisdicción de la ciudad, de acuerdo con el procedimiento notarial y a la autorización correspondiente tenían también pleno efecto y validez en la misma.

En 1719, por ejemplo, Cabrera Cañete y de Lorca, ambos escribanos propietarios, se alternaron irregularmente en la escribanía del cabildo, siendo los encargados de labrar las actas.

\section{Cuadro 3}

Ventas y arrendamientos de escribanías en Corrientes

\begin{tabular}{|c|c|c|c|c|}
\hline \multirow[b]{2}{*}{ Escribano } & \multicolumn{2}{|c|}{ Año } & \multirow[b]{2}{*}{ Precio } & \multirow[b]{2}{*}{ Calidad } \\
\hline & Inicio & Cese & & \\
\hline Pedro Bautista Casajús & 1714 & 1715 & & Arrendamiento \\
\hline Joseph Andrés Lorca & 1717 & 1721 & $1350 \$$ & Propiedad \\
\hline \multirow{2}{*}{$\begin{array}{c}\text { Adrián Cabrera } \\
\text { Cañete }\end{array}$} & 1719 & 1723 & & Propiedad \\
\hline & 1739 & 1743 & $450 \$$ & Propiedad \\
\hline Francisco Solano Cabral & 1725 & 1727 & & Arrendamiento \\
\hline \multirow{2}{*}{$\begin{array}{c}\text { Pedro Pérez } \\
\text { Serrano }\end{array}$} & 1731 & 1734 & $50 \$ c / a$ & Arrendamiento \\
\hline & 1737 & 1739 & $50 \$ c / a$ & Arrendamiento \\
\hline
\end{tabular}

Fuente: elaboración propia en base a Actas Ctes.

El precio que se pagó por adquirir una escribanía, generalmente, fue alto en comparación a los oficios del cabildo. Esto se relacionó con la ardua disputa ocasionada en las pujas durante el remate de este oficio. Fue persistente y reñida, por ejemplo, la puja entre Joseph Andrés Lorca y Juan Núñez de Ábalos, lo que produjo la suba del precio de la escribanía a 1350 pesos por parte del primero. Lamentablemente no disponemos datos referentes al monto del pago que realizaron por la escribanía Adrián Cabrera Cañete en la primera oportunidad en 1719 y Francisco Solano Cabral en 1725.

Por otra parte, sabemos que Pedro Bautista Casajús arrendó el oficio de escribano, mientras que Pedro Pérez Serrano hizo lo mismo en dos periodos (17311734 y 1737-1739).

\footnotetext{
${ }^{22}$ Según Álvarez y González el nombre "escribano de número" proviene del derecho que las ciudades castellanas obtuvieron para limitar la cantidad o número de escribanos que era designados por los reyes, proviniendo de allí su denominación. Estos funcionarios, a diferencia de los escribanos del rey o del reino, podían ejercer sus funciones exclusivamente en el ámbito local donde fueron designados. p. 557.
} 
Realizando una mirada colectiva sobre los remates y adquisiciones de la escribanía, debemos preguntarnos con respecto a los motivos por el cual fue tan disputado este oficio, entre los escasos vecinos que se hallaban en condiciones de adquirirlo, como así también puntualizar por qué se pagó un monto relativamente elevado por éste. Si tenemos en cuenta que los escribamos, como dijimos previamente, eran los encargados exclusivos de labrar los documentos públicos, como testamentos, contratos, expedientes judiciales, además de las actas del cabildo, y que por cada uno de éstos cobraba emolumentos a los suscriptores o al ayuntamiento, es comprensible entender el interés que existió sobre este oficio, siendo que la compra de una escribanía significó, en términos rentables, una inversión que a la larga permitiría no sólo recuperar lo desembolsado sino también obtener mayor ganancia y, en última instancia, un ingreso regular de recursos económicos ${ }^{23}$.

\section{El remate del oficio honorífico de alférez real}

El oficio de alférez real tuvo un marcado carácter honorífico por lo que fue muy codiciado por los vecinos de las ciudades indianas. Entre sus funciones más relevantes se hallaba el ser el encargado exclusivo de pasear el real estandarte en las celebraciones religiosas o profanas prescriptas, que como su nómina lo indica representaba al monarca hispánico en la ciudad (Porro Girardi, 2005 y Traynor Balestra, 2004). El juramento que debía realizar previamente a ser recibido en este oficio, estipulaba que el alférez real tendrá en guardia y custodia el real estandarte Y no lo entregará a persona alguna que no lo deba entregar lexitimamente, ni lo enarbolara sino en los casos dispuestos en la forma que loan tenido y guardado sus antecesores... ${ }^{24}$

Durante el periodo que estudiamos el oficio de alférez real fue adquirido en propiedad en dos oportunidades. Baltasar Maciel compró el oficio en 600 pesos en 1713, desempeñándose en él hasta 1718, cuando hizo renunciación del oficio de alférez real en propiedad por Su Magestad. ${ }^{25}$

\section{Cuadro 4 \\ Alfereces reales propietarios del Cabildo de Corrientes}

\begin{tabular}{|c|c|c|c|}
\hline \multirow{2}{*}{$\begin{array}{c}\text { Alférez } \\
\text { Real }\end{array}$} & \multicolumn{2}{|c|}{ Años } & \multirow{2}{*}{ Precio } \\
\cline { 2 - 3 } & Inicio & cese & $600 \$$ \\
\hline Baltasar Maciel & 1713 & 1718 & $650 \$$ \\
\hline Gregorio de Ocampo y Ascona & 1720 & 1737 & 6 \\
\hline
\end{tabular}

Fuente: elaboración propia en base a Actas Ctes.

\footnotetext{
${ }^{23}$ AGPC, AC 19, f. 2 v.

${ }^{24}$ AGPC, AC 15, f. 35.

${ }^{25}$ AGPC, AC 16, f. 82v.
} 
Gregorio de Ocampo y Ascona, por su parte, se desempeñó como alférez real, con algunos breves intervalos de ausencia, durante diecisiete años (1720-1737). Compró el oficio en un remate reñido, donde participó junto a Fernando de Esquivel y Cabrera, vecino correntino que también estuvo hondamente interesado en adquirir en propiedad el alferazgo. El monto que se pagó por el oficio real en esta oportunidad ascendió a 650 pesos $^{26}$.

\section{La venta del oficio de Alcalde provincial de la santa hermandad}

En Indias existieron dos clases de alcaldes de la santa hermandad. Por un lado, los provinciales, los cuales ejercieron sus funciones en la campaña de una provincia y poseyeron, en la mayoría de las ocasiones, voz y voto en los ayuntamientos hispanoamericanos, y, por el otro, los de partido, que desempeñaban su función en los pagos o parroquias de cada localidad (Levaggi, 2009).

En Corrientes, existieron dos alcaldes de partido de la santa hermandad, los cuales eran elegidos por los capitulares y existieron, al menos como función, desde los orígenes de la ciudad. A diferencia de estos, los alcaldes provinciales de la santa hermandad en el Río de la Plata aparecieron en las primeras décadas del siglo XVII con el objetivo de aumentar el número de oficios capitulares, dado que anteriormente no se registra su presencia (Zorraquín Becú, 1959).

\section{Cuadro 5}

Alcaldes provinciales de la santa hermandad propietarios

\begin{tabular}{|c|c|c|c|}
\hline \multirow{2}{*}{$\begin{array}{c}\text { Alcalde provincial } \\
\text { de la santa hermandad }\end{array}$} & \multicolumn{2}{|c|}{ Años } & \multirow[b]{2}{*}{ precio } \\
\hline & inicio & cese & \\
\hline Roque de Herrera & 1713 & 1719 & $2600 \$$ \\
\hline Juan Crisóstomo Dicido y Zamudio & 1722 & 1725 & $2600 \$$ \\
\hline Jorge Martínez de Ibarra & 1725 & $1744 / 45$ & $2600 \$$ \\
\hline
\end{tabular}

Fuente: elaboración propia en base a Actas Ctes

Tres fueron los vecinos de Corrientes que se desempeñaron como alcalde provincial de la santa hermandad en este periodo. No obstante, existió una conexión entre los tres vecinos que se desempeñaron en este cargo por medio de la renunciación que fueron realizando sucesivamente del oficio uno en otro. De este modo, Roque de Herrera, quien adquirió el oficio en 1713, renunció al mismo en 1722 en Juan Crisóstomo de Dicido y Samudio. Éste, a su vez, ejerció su derecho a renunciar el oficio de alcalde provincial de la santa hermandad en 1725, por algunas causas que al

\footnotetext{
${ }^{26}$ Véase AGPC, AC 17 , fs. 22-27v.
} 
presente le mueben ${ }^{27}$ a favor de Jorge Martínez de Ibarra. ${ }^{28}$

Roque de Herrera abonó en la Caja de la Real Hacienda por el oficio de alcalde provincial de la santa hermandad, 2600 pesos. Tanto Dicido y Zamudio como Martínez de Ibarra debieron pagar, en total, la misma cifra. Se debe tener en cuenta que de acuerdo con lo estipulado por las leyes reales, el beneficiario de la renunciación debía abonar en la Caja Real el monto equivalente a un tercio (33,33\%) del precio del remate del oficio, mientras que al antiguo propietario debía restituirle "dos tercios" (es decir el $66,66 \%$ ) del monto por el cual adquirió el oficio.

\section{El remate del oficio del alguacil mayor}

La función principal del alguacil mayor era velar por la tranquilidad de la ciudad y estar a cargo de la cárcel pública (González Muñoz, 1994); por dicho motivo, en la ceremonia de su recibimiento se le hacía entrega, a quien se nombrase como alguacil mayor, de la vara de la real justicia, llaves, prisiones, carceles y pressos ${ }^{29}$.

\section{Cuadro 6}

Alguaciles mayores propietarios

\begin{tabular}{|l|c|c|c|}
\hline \multirow{2}{*}{\multicolumn{1}{|c|}{ Alguacil mayor }} & \multicolumn{2}{c|}{ Años } & \multirow{2}{*}{ Precio } \\
\cline { 2 - 3 } & \multicolumn{2}{|c|}{ Inicio cese } & \\
\hline \multirow{2}{*}{$\begin{array}{l}\text { Juan Eusebio } \\
\text { de Chávez }\end{array}$} & 1714 & 1720 & \\
\cline { 2 - 3 } & 1735 & $1742 / 3$ & $10 \$$ c/a \\
\hline Juan Jil Fernández de Leisa & 1721 & 1727 & $400 \$ ?$ \\
\hline Adrián Cabrera y Cañete & 1728 & 1734 & $425 \$$ \\
\hline
\end{tabular}

Fuente: elaboración propia en base a Actas Ctes

Durante este periodo se vendió el oficio de alguacil mayor en tres oportunidades, mientras que en otra se designó a un vecino para que se desempeñara en el oficio.

Juan Eusebio de Chávez, el mismo que anteriormente hemos señalado como comprador de un regimiento, adquirió en propiedad el oficio de alguacil mayor en 1721. Sin embargo, seis años después se vio obligado a cesar en el cargo dado que no recibió y por consecuencia no presentó ante el cabildo la confirmación real ${ }^{30}$. Igual suerte corrió Juan Jil Fernández de Leisa, quién se desempeñó en el oficio como propietario posteriormente, entre 1721 y $1727^{31}$.

\footnotetext{
${ }^{27}$ AGPC, AC 18, f. 185v.

${ }^{28}$ AGPC, AC 16, f. 17.

${ }^{29}$ AGPC, AC 18, f. 98.

${ }^{30}$ AGPC, AC 22, f. 123.

${ }^{31}$ AGPC, AC 19, f. 150.
} 
Quien finalmente adquirió este oficio de alguacil mayor fue Adrián Cabrera Cañete, el mismo vecino que anteriormente había rematado en su favor la escribanía de número, por la suma de 425 pesos $^{32}$. La falta de confirmación real también fue el motivo reiterado del cese de Cabrera Cañete en el oficio de alguacil mayor en 1734.

Ante esta vacancia, el cabildo correntino, durante la sesión del 28.V.1735, trató sobre la necesidad que ai en esta ciudad de ministro de justicia que ejecute los mandamientos de ella i de los demas juezes de comizion y caja rreal desde que vaco el que obtenía de alguacil maior don Adrían Cañete pues aunque se a traido al pregon no se ha conseguido hasta oi comprador en la propiedad ni en el arrendamiento.

Para solucionar la cuestión, el cuerpo capitular determinó escribir al superior gobierno, teniendo presente que en semenjante caso a cuia constumbre de que los señores governadores de esta provincia han hecho nombramiento de alguacil maíor con solo el gravamen de pagar en la rreal caxa de esta ciudad, un tanto acordamos se informe a su señoria con copia de este acuerdo y certificación del tesorero de la rreal hazienda de lo que entera... ${ }^{33}$

El gobernador del Río de la Plata, Miguel de Salcedo y Sierra Alta, respondió rápida y favorablemente a la petición del cabildo correntino y nombró a Juan Eusebio de Chávez alguacil mayor en 1735, en el entretanto se provea dicho oficio en propiedad $y$ arrendamiento. El monto estipulado por el uso del oficio fue de 10 pesos por cada año en que ocupare el cargo. ${ }^{34}$

\section{Otros oficios capitulares enajenados}

Además de los oficios ya mencionados, se remataron otros como los de depositario general y fiel ejecutor. El depositario general, por su parte, era el encargado de recibir y custodiar los bienes en depósito por fallecimiento sin herederos, procesos y secuestros judiciales, entre otras cosas. (Moutokías, 2000)

\section{Cuadro 7}

Remates de depositario general y fiel ejecutor

\begin{tabular}{|l|l|c|c|c|}
\hline \multirow{2}{*}{\multicolumn{1}{|c|}{ Vecino }} & \multicolumn{2}{c|}{ Años } & \multirow{2}{*}{ Oficio } & \multirow{2}{*}{ Precio } \\
\cline { 2 - 3 } & Inicio & Cese & & \\
\hline Diego Fernández & 1713 & 1719 & Depositario general & $325 \$$ \\
\hline Fernando Gómez Durán & 1724 & 1724 & Depositario general & $325 \$$ \\
\hline Juan Pessoa y Figueroa & 1726 & 1731 & Depositario general & $335 \$$ \\
\hline Melchor Valdez Miranda & 1732 & 1747 & Depositario general & \\
\hline Pedro de Arriola & 1715 & 1723 & Fiel ejecutor & \\
\hline
\end{tabular}

Fuente: elaboración propia en base a Actas Ctes.

\footnotetext{
${ }^{32}$ AGPC, AC 19, fs.139-146v.

${ }^{33}$ AGPC, AC 22, f. 85.

${ }^{34}$ AGPC, AC 22, f. 123.
} 
Este oficio comenzó a rematarse recién en el siglo XVIII, ya que no encontramos indicios ni dato alguno que nos indique que anteriormente haya existido o haya sido enajenado. Cuatro vecinos se desempeñaron en este oficio como propietarios (Diego Fernández, Fernando Gómez Durán, Juan Pessoa y Figueroa y Melchor Valdez Miranda). Como se observa, el precio pagado por el oficio de depositario general fue ascendiendo levemente, en virtud a los sucesivos remates, de 325 a 335 pesos.

No tenemos datos referentes al monto pagado por Melchor Valdez Miranda, sin embargo podemos suponer que el precio del mismo, sino fue similar a éstos, fue un tanto superior. Este vecino último, fue quien se desempeñó por mayor tiempo en el puesto de depositario general, logrando alcanzar los quince años, dado la confirmación del rey en este cargo. A excepción de Gómez Durán que fue cesanteado por no presentar el título ante el cabildo dentro del plazo establecido, por lo cual no llegó a tomar posesión efectiva del oficio ${ }^{35}$, los otros dos vecinos no llegaron a superar los seis años debido a que no pudieron presentar la confirmación real en sus puestos.

Por otra parte, el oficio de fiel ejecutor, dentro de la organización funcional del cabildo, estuvo a cargo de inspeccionar los abastos públicos de la ciudad, cuidando que no existiera escasez de un producto y sobre todo de controlar que los comerciantes del mercado local utilizaran con exactitud los pesos y las medidas, como así también de que se vendieran los productos de acuerdo con el precio estipulado por el ayuntamiento (Zorraquín Becú, 1959).

Antes de exponerse a la venta el oficio de fiel ejecutor, este era un cargo que recaía en cada uno de los regidores por turno bimestrales. Sin embargo, pareciera ser que no fue un puesto muy codiciado en Corrientes a juzgar porque solo un vecino, Pedro de Arriola, remató este oficio en propiedad, desempeñándose en el mismo durante el extenso periodo 1715-1723. No hemos hallado datos que nos permitan conocer el precio que desembolsó este vecino por la compra de este oficio. También ignoramos ciertos datos de su desempeño en el oficio, como por ejemplo, en qué fecha exacta asumió el puesto y, así también, cuándo cesó exactamente en el mismo y por qué motivos concretos lo hizo. Lo último que sabemos de este Pedro de Arriola es que en 1723 solicitó licencia al cabildo correntino para viajar a Chile. De ahí en más, no hallamos datos concretos de la actividad pública de este vecino ${ }^{36}$.

\section{La renunciación de oficios capitulares}

La adquisición de los oficios capitulares, por otra parte, otorgaba inherentemente el beneficio de la renunciación del mismo ${ }^{37}$. Por renunciación se entendía el derecho a transferir el oficio en propiedad, con las mismas honras y privilegios, a un tercero (Tomás y Valiente, 1986).

\footnotetext{
${ }^{35}$ AGPC, AC 18, fs. 132 y 193.

${ }^{36}$ Véase AGPC, AC 17, f. 149.

${ }^{37}$ Recopilación de las leyes de los Reinos de Indias. Consejo de la Hispanidad, 1943, t. II, libro VIII, título 21, ley I.
} 
Aún más, en el cabildo de Corrientes, en ninguno de los casos estudiados en este periodo hemos hallado que se realizó la renunciación de un oficio dentro del grupo familiar. El motivo más común por el cual los oficios propietarios del cabildo correntino cesaron en el desempeño de su cargo fue por falta de confirmación del Real Consejo de Indias, dado que las leyes reales establecían que la pena impuesta al oficial de no llevar confirmacion del oficio es perdimiento del y venderse por quenta de Su Majestad como devuelto a su Real Patrimonio, y ganar del procedido, el un tercio, dandose los otros dos al dueño del oficio por defecto de averse pasado el termino de confirmación... ${ }^{38}$

De los 37 casos de enajenación de oficios que hemos estudiado, 10 fueron cesanteados en su cargo por este motivo, lo cual nos indica que, al igual que en el siglo XVII, ésta continuó siendo una problemática aún presente y permanente en este periodo.

Solo un número reducido de cinco capitulares llegó a conseguir efectivamente la confirmación del Rey, si bien, la mayor parte de los capitulares alegaron haber realizado los trámites correspondientes para conseguir la definitiva revalidación del título y de no haber obtenido respuesta alguna.

No sabemos exactamente cuáles pudieron ser los motivos por los cuales únicamente un número limitado consiguió la confirmación real y el resto no. ¿Existieron, acaso, dificultades en las comunicaciones entre la Metrópoli y la periférica ciudad de Corrientes, lo que redundó en el impedimento para conseguir la ratificación del monarca? Las gestiones para conseguir la aprobación real se debía realizar, en el caso de Corrientes, por estar incluido en la jurisdicción administrativa del Río de la Plata, en la Real Audiencia de Charcas. En la mayoría de los casos, se realizaron estos trámites por intermedio de un apoderado, quien en nombre del propietario presentaba el título otorgado por el gobernador y demás documentaciones pertinentes para que este organismo lo elevara al Consejo de Indias. Por este motivo, para pagar los costos del envío y trámites burocráticos, el interesado debía entregar un donativo correspondiente en la Caja Real de la ciudad de La Plata, que lejos de ser una contribución voluntaria, conformaba en realidad un impuesto ineluctable, el cual se señalaba en cien pesos. ${ }^{39}$

Dado que, se estimaba, tardaría un tiempo prolongado la tramitación final y la recepción del mismo en el capitular propietario, la Real Audiencia, ubicada en Charcas, otorgaba a este un título provisorio en el cual se ordenaba a los gobernantes y al cabildo local que no se impidiera ni separase al capitular propietario de su puesto, aunque ya hubieran transcurrido los seis años de plazos estipulados por el título original ${ }^{40}$.

Asimismo, para dar un panorama más completo de la realidad debemos afirmar que 8 de estos 37 propietarios renunciaron a sus oficios; mientras que dos (Juan Martín Cordero y Juan Crisóstomo Dicido y Zamudio) los hicieron en algún vecino, seis (Diego

\footnotetext{
${ }^{38}$ AGPC, AC 22, f. 12v.

${ }^{39}$ Véase Reales provisiones de confirmación de oficios en AGPC, Juan Martín de Cordero, AC 16, fs. 140141v. Francisco Molina Salazar en AC 18, fs. 175-177v.

${ }^{40}$ AC 18 , f. $175 \mathrm{v}$.
} 
Fernández, Ignacio de Soto, Joseph de Lorca, Joseph Antonio Miérez y Gregorio de Ocampo y Ascona, en dos oportunidades) lo efectuaron en cabeza de Su Majestad. En esto casos, quien nuevamente comprara el oficio debía reintegrar al renunciante el tercio del valor por el cual remató el oficio.

Por otra parte, dos vecinos (Pedro Ruiz de Bolaños y Pedro de Arriola) perdieron sus oficios por ausentarse de la ciudad correntina por mayor tiempo de lo permitido, y otros dos (Gerónimo Martínez de Ibarra y Francisco Molina Salazar) cesaron por fallecimiento. Sólo a uno de ellos (Juan de Vargas Machuca) se le fue rematado el título por sentencia judicial. De diez casos no hemos podido hallar datos concretos referentes al cuál fue el motivo del cese, pese a que se pueden realizar algunas conjeturas.

\section{Motivo de cese de los capitulares propietarios}

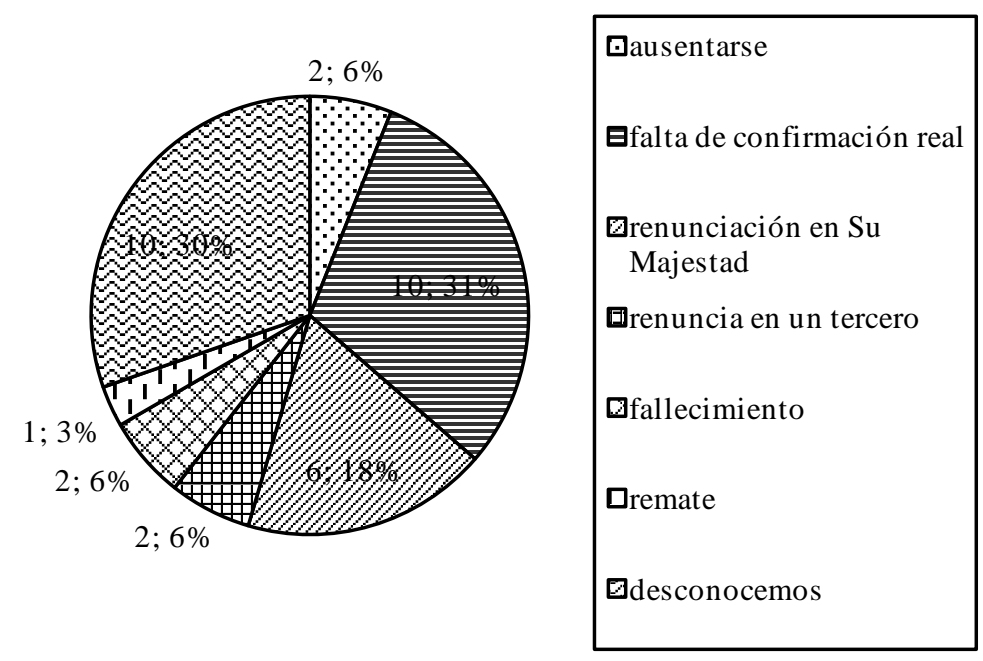

Elaboración propia en base a AGPC, AC

\section{Configuración socioeconómica}

De acuerdo con García Bernal, la implementación del sistema de venta y renunciación de oficios inició en Hispanoamérica una nueva etapa en la historia de los cabildos coloniales, dado que modificó la forma de acceder a los mismos y esto redundó, a su vez, en una alteración de su estructura y composición socioeconómica (García Bernal, 2000).

Debemos preguntarnos en estos momentos, si esta situación ocurrió o no en Corrientes. Si establecemos una comparación social entre los vecinos que sólo ocuparon un puesto en el ayuntamiento correntino a fines del siglo XVII y primera década del XVIII y aquellos que los compraron remataron un oficio, notaremos algunas diferencias, pero sobre todo algunas vinculaciones notables entre ambos grupos. 
Los primeros vecinos que se desempeñaron como cabildantes pertenecieron al grupo de los denominados "beneméritos" o descendientes de los primeros pobladores y conquistadores de la ciudad. Algunos de éstos aun poseían en propiedad títulos de encomiendas. Entre estos podemos nombrar a Ambrosio de Acosta, Víctor de Figueroa, Alejandro de Aguirre, Juan Gómez de Meza, Pedro González de Alderete, quienes en varias ocasiones ocuparon los puestos de alcaldes o regidores cadañeros durante el periodo señalado. Cabe aclarar que de este grupo (Acosta y Figueroa), el gobierno superior de Buenos Aires nombró a los capitulares provisorios hasta tanto aparecieran los propietarios.

Por otra parte, comenzaron a aparecer en el cabildo correntino, por medio de la adquisición en propiedad de un oficio capitular, un nuevo grupo de vecinos que en un principio no estuvieron relacionados con los beneméritos. Sin embargo, no podemos hablar que en el cabildo correntino existió un desplazamiento del primer grupo de vecinos por este nuevo; ni siquiera un desinterés o imposibilidad de comprar un oficio capitular, dado que un número importante de "descendiente de primeros pobladores" lo efectuó (Salinas, 2004).

Contrariamente a un desplazamiento de los antiguos vecinos por los nuevos, debemos afirmar que se produjo una vinculación entre ambos grupos de forma paulatina. Un ejemplo es el de Juan Crisóstomo Dicido y Zamudio, comerciante de origen peninsular, quien para afianzar su relación con el grupo de los beneméritos y disfrutar de los beneficios de éstos, contrajo matrimonio con Ana Maciel, perteneciente a una familia tradicional correntina ${ }^{41}$.

Por este motivo, como nos indica una lectura profunda de las fuentes, debemos afirmar que el grupo social al cual pertenecieron los regidores propietarios de Corrientes durante la primera parte del siglo XVIII fue heterogéneo, en donde los "nuevos vecinos" pudieron integrarse al cabildo y aunar los intereses con el grupo de los descendientes de los primeros conquistadores. También pudimos comprobar que este grupo de vecinos de diverso origen tuvo en común la actividad económica en la que se desempeñaron. Ya dijimos, con anterioridad, que la gran mayoría de los vecinos que compraron un oficio del cabildo poseyeron estancias o chacras dentro de la jurisdicción correntina, y que la producción de estas unidades agrícolas les otorgó la base material para solventar el importe de los remates (Maeder, 1986)

Como en todos los grupos sociales oligárquicos, una vez que se consolidó este grupo capitular, se intentaron crear lazos solidarios para favorecer a los integrantes del cabildo, como ser el otorgar licencias para ausentarse momentáneamente del cabildo para atender la producción en su estancia o chacra.

Así también, fue común que se eligiera como alcaldes ordinarios a los mismos cabildantes propietarios, pese a las prohibiciones de las leyes reales al respecto. Esto nos demuestra que sí bien por leyes reales no se enajenaron los puestos de justicias, en la práctica esto no se cumplió, al menos en determinados periodos, dado que el grupo que pudo acceder al cabildo sorteó los mecanismos institucionales, logrando controlar,

\footnotetext{
${ }^{41}$ AGPC, AC 23, f. 218 y Protocolo 11, f. 176.
} 
además, las mismas alcaldías por medio de la elección de los mismos capitulares propietarios en los puestos de alcaldes, logrando así un beneficio adicional.

Por dicho motivo, Bruno Mauricio de Zavala, gobernador del Río de la Plata, anuló en 1729 la elección de alcalde ordinario hecha en Francisco Molina Salazar, regidor propietario, dado que esta acción se hallaba contra leyes reales el que lo puedan ser los capitulares los quales se hallan corroborados con una real provision de la Real Audiencia y chancilleria de las Charcas ${ }^{42}$.

Sin embargo, no fue la primera ni la última vez que los capitulares propietarios fueron electos para desempeñarse en la alcaldía ordinaria, si bien debemos señalar que esta elección comenzó a realizarse con mayor disimulo.

El grupo de capitulares se caracterizó de este modo por poseer una estructura permeable, permitiendo la paulatina integración del grupo de los recién llegados, como continuó sucediendo a lo largo del siglo XVIII. No queremos afirmar que el grupo que se acaparó los oficios capitulares en este periodo haya sido sosegado y que no existieses disensiones entre sus miembros. Por el contrario, se produjeron distintos conflictos en el grupo capitular, como quedó de manifiesto en las sesiones donde se realizaban las tachas de los posibles vecinos a ser electos y las elecciones capitulares; sin embargo, siempre se buscó aunar sus criterios o al menos tolerar las diferencias con el objetivo de obtener los beneficios que le brindaba la relevancia de ser parte del cuerpo capitular.

No obstante, el funcionamiento y la continuación de sus miembros en esta institución municipal no dependió exclusivamente de sus integrantes, también debemos considerar la autoridad del gobierno superior de Buenos Aires y sobre todo de las instituciones reales, como la Audiencia Real y Consejo de Indias, que estuvieron facultados para obstaculizar una política o cesantear a una miembro del cabildo, si no se cumplían las prescripciones legales.

Al margen de esto, el cabildo correntino supo maniobrar, amparado por la distancia y su marginalidad, y hacer valer sus intereses, o mejor dicho de los intereses de aquellos que formaron parte de este organismo municipal.

\section{Consideraciones generales}

Pese a la fragmentación y limitación de los datos con lo que trabajamos, sobre todo si comparamos con otras realidades hispanoamericanas, estamos en condiciones de presentar algunas conclusiones a modo de cierre de este trabajo.

1. Hacia fines del siglo XVII, los oficios de regidores del cabildo de Corrientes vacaron por falta de confirmación real. Por dicho motivo, este organismo municipal continuó funcionando exclusivamente con los dos alcaldes ordinarios. Ante esta situación se hizo necesario solicitar al gobierno superior de Buenos Aires que designara, en virtud de las reales provisiones que lo facultaban, a vecinos para que ejerzan estos cargos. Por este motivo, el gobernador de

\footnotetext{
${ }^{42}$ En AGPC, AC 19, f. 205.
} 
Buenos Aires nombró a algunos vecinos para que ocuparan distintos puestos en el cabildo hasta tanto aparecieran rematadores de los mismos.

2. En el primer tercio del siglo XVIII, en Corrientes, comenzaron a aparecer paulatinamente distintos vecinos con títulos de capitulares propietarios. Esto se relacionó con la expansión de la frontera ganadera correntina, dado que los principales adquirientes poseyeron en propiedad una chacra o estancia, cuya producción le permitió solventar los cuantiosos desembolsos en el remate de los oficios.

3. Distintas leyes reales permitieron que en ciudades periféricas en donde no circulaba la moneda metálica se pagasen el precio de los oficios vendibles del cabildo con las "monedas de la tierra". El principal medio de intercambio en la ciudad de Corrientes con las que se abonaron los distintos oficios capitulares fue el lienzo de algodón y otros productos agrícolas, como la yerba.

4. Si bien, nuevos vecinos que se diferenciaban de los tradicionales hijos y descendientes de los primeros pobladores de Corrientes remataron en propiedad distintos oficios del cabildo, no podemos decir que se produjo un desplazamiento del primer grupo por el segundo. Existieron vecinos de ambos grupos que accedieron al cabildo por medio de la compra de un oficio capitular. Uno y otro, con el transcurrir del tiempo, supieron aunar sus intereses. Por lo cual, podemos caracterizar al grupo social de capitulares propietarios como heterogéneo, cuyos miembros poseyeron en propiedad unidades de producción como estancias o chacras, lo que le brindó un relativo bienestar económico y un medio para solventar los gastos por el oficio adquirido.

\section{Fuentes y bibliografía \\ Fuentes \\ Inéditas \\ Archivo General de la Provincia de Corrientes, \\ Actas Capitulares. Tomos 10 a 25 \\ Protocolos, Tomo 10 y 11.}

\section{Éditas}

Recopilación de las Leyes de los Reynos de Indias. Consejo de la Hispanidad, 1943.

Ramón de la Sagra. Historia económico-política y estadística de la Isla de Cuba o sea de sus progresos en la población, la agricultura, el comercio y las rentas, Habana, 1831.

\section{Referencias Bibliográficas}

Aguilar Piñal, Francisco. 1989. Historia de Sevilla: Siglo XVIII, volumen 6. $3^{\circ}$ ed. Universidad de Sevilla, Sevilla.

Álvarez, María Jesús y González, Coca. La figura del escribano - Madrid, España. OEA, Lección de clausura del XV curso sobre organización y administración de Archivos Históricos [en línea] 1987, junio, [citado en jul. 2010]. Disponible en URL: http://www.dialnet. 
Pozzaglio. La venta y el nombramiento de oficios en el cabildo de Corrientes.

unirioja.es/servlet/fichero_articulo? codigo $=801032$

García Bernal, Manuela Cristina. 2000. Las élites capitulares indianas y sus mecanismos de poder en el siglo XVII, Anuarios de Estudios Americanos, Vol. 57, tomo LVII, 1, CSIC, Sevilla, España.

Gelman, Jorge. 2003. El régimen monetario. Nueva Historia de la Nación Argentina. 3. Periodo español (1600-1810). Academia Nacional de la Historia, Buenos Aires, Planeta.

González Muñoz, Victoria. 1994. Cabildos y grupos de poder en Yucatán, (siglo XVII). Sevilla, V Centenario del Descubrimiento de América.

Guajardo Fajardo Carmona, María de los Ángeles. 1995. Escribanos en Indias durante la primera mitad del siglo XVI. Vól.1. Colegio Notariales de España.

Labougle, Raúl de. 1978. Historia de San Juan de Vera de las Siete Corrientes (1588-1814). Buenos Aires.

Levaggi, Abelardo. 2009. La alcaldía de hermandad en el Virreinato del Río de La Plata (17761810) (Casuística y jurisprudencia). Revista de Estudios históricos-jurídicos, $\mathrm{n}^{\circ} 31$, Valparaíso, Chile.

Maeder, Ernesto J.A. 1961. "La ciudad de Corrientes descripta por viajeros y cronistas, entre 1750 y 1828 ”. Nordeste. $N^{\circ} 1$. Resistencia, Chaco, Facultad de Humanidades Universidad Nacional del Nordeste.

1986. La formación de la economía correntina (siglos XVI a principios del XIX). Buenos Aires, Emilio Perina.

y Gutiérrez, Ramón. 2003. Atlas del desarrollo urbano del Nordeste Argentino. Resistencia, Chaco, Instituto de Investigaciones Geohistóricas - Conicet Universidad Nacional del Nordeste.

Moutokias, Zacarías. 2000. Gobierno y sociedad en el Tucumán y el Río de la Plata, 15501800”. En: Enrique Tandeter (dir.) Nueva Historia Argentina. 2. La sociedad colonial, Buenos Aires, Sudamericana.

Porro Girardi, Nelly. 2005. El estandarte real de las ciudades indianas: Un símbolo jurídicopolítico. Actas del XV Congreso del Instituto Internacional de Historia del Derecho Indiano. Diputación de Córdoba, Universidad de Córdoba.

Salinas, María Laura. 2004. "Élites y encomiendas en Corrientes en la segunda mitad del siglo XVII". En: XXIV Encuentro de Geohistoria Regional. Instituto de Investigaciones Geohistóricas - Conicet. Resistencia, 9, 10 y 11 de septiembre, 2004. pp. 523-562.

Tomás y Valiente, Francisco. 1982. La venta de oficios en Indias (1492-16069). Colección Estudios de Historia de la Administración, Madrid.

Traynor Balestra, María Mercedes. 2004. El alférez real en el cabildo de la ciudad de Vera. Anales de la Junta de la Historia de la Provincia de Corrientes, № 6, Corrientes, Moglia, pp.383-394.

Zorraquín Becú, Ricardo. 1959. La organización política Argentina en el periodo hispánico, Buenos Aires, Emecé. 